XXXI. Observations on the "Bitentaculate Slug" of New Zealand (Limax bitentaculatus, Quoy and Gaimard; Janella antipodarum, Gray; "Aneiteum Slug"? ?, Macdonald). By Charles Knight, Esq., F.L.S.

Read June 2nd, 1859.

Auckland, New Zealand, 27th December, 1858.

DeAR SiR,

I HAVE lately compared Mr. J. D. Macdonald's observations on the Bitentaculate Slug found at Aneiteum (Annals and Mag. Nat. Hist. 2 ser. xviii. p. 38, 1856) and Dr. Gray's description of Janella antipodarum (Annals and Mag. Nat. Hist. 2 ser. xii. p. 414, 1853) with the living Gasteropod found in New Zealand, and trust that the following notes and the accompanying drawing will interest the members of the Society.

The New Zealand mollusk is little more than an inch in length. The mantle (?) covers the whole of the upper surface. The space which Dr. Gray describes as existing between the edge of the mantle and the foot, is on the under surface of the animal; so that the edge of the mantle forms the outline of the body as seen from above. The mantle (?) is mottled with light-coloured spots, the larger of which are at regular intervals, and are at times elevated above the surface in sharp conical points (fig. 14). The " raised margin" of Dr. Gray's description is due to the effects of alcohol.

In alcohol the animal becomes subcylindrical, and answers to the description of Dr. Gray and to that of Lamarck (Anim. sans Vert. 2nd ed. vol. vii. p. 723, Limax bitentaculatus, Quoy).

The aperture of respiration $(d, f i g .3)$ is on the right side of the slightly depressed roof of the pulmonary sac. There are four small, semitransparent, calcareous (?) granules in the anterior wall of the pulmonary sac (fig. 13); and immediately anterior to the sac is a small foramen ( $a$, fig. 3), affording passage to a fluid which flows in pulsatory waves over its roof. Generally this pulsatory movement occurs at regular and frequent intervals; and the wave extends around the pulmonary aperture, as if a limpid fluid were propelled under the glutinous secretion which covers and protects the body of the mollusk.

The buccal mass is armed above with a single horny plate or tooth (figs. 7, 8). In feeding, the animal forces forward the buccal mass, and scrapes or hoes up with the horny plate the surface of the substance it is feeding on.

The lingual sac, instead of being furnished with the single, symmetrical, tubular appendage of the common Slug of these Islands, has posteriorly two delicate, plicated, convolute appendages armed with transverse rows of dental processes (figs. 11, 12). The sac itself is furnished with a complete armature of rasps (figs. 9, 10) placed in numerous transverse parallel rows, which meet in the median line at a very obtuse angle. Each rasp has several minute tceth, and is set diagonally in the row, as are also the spine-like plates from which the minute rasps project (fig. 10). 
There is no such mantle as that described by Mr. Macdonald in the Aneiteum Slug as covering the roof of the pulmonary sac; but there is a depression instead of it, and the roof of the sac is extremely thin.

In deference to the views of Dr. Gray, I have termed the covering of the whole of the "pper surface of the animal "the mantle;" but, taking into consideration that it would be extraordinary that the eyes of the animal should be protruded through the secretory organ of the shell, this interesting Gasteropod may more probably be regarded as quite naked.

Believe, dear Sir, yours very truly,

J. J. Bennett, Esq., F.R.S.,

Charles KNight.

Secretriry of the Linnean Society.

EXPLANATION OF THE PLATE.

\section{TAB. LXVI.}

Figs, 1, 2. Dorsal aspect of Janella antipodarum.

Fig. 3. Lateral view.

Fig. 4. Portion of dorsum, enlarged, and showing-

$a$. Small foramen anterior to pulmonary sac.

d. Respiratory orifice.

Fig. 5. Lingual sac laid open.

$a$. Plicated folds.

$b$. Transverse rasp-like processes.

Figs. 6, 7. Horny plate of buccal mass.

Fig. 8. Lingual sac and its tubular appendage.

$a$. Tubular appendage.

b. Sac.

Fig. 9. Armature of lingual sac magnified.

Fig. 10. Magnified view of rasps.

g. Rasp.

$f$. Plate.

Figs. 11, 12. Dental processes and plates on plicated appendages:

Fig. 13. Calcareous particles in wall of respiratory cavity.

Fig. 14. Conical cutaneous papilla. 

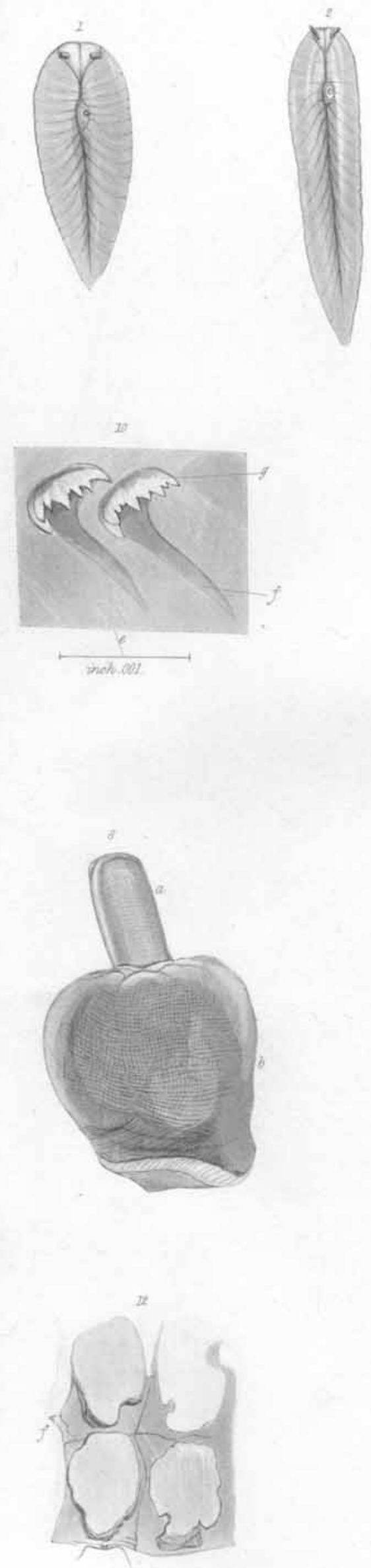

Cobight det

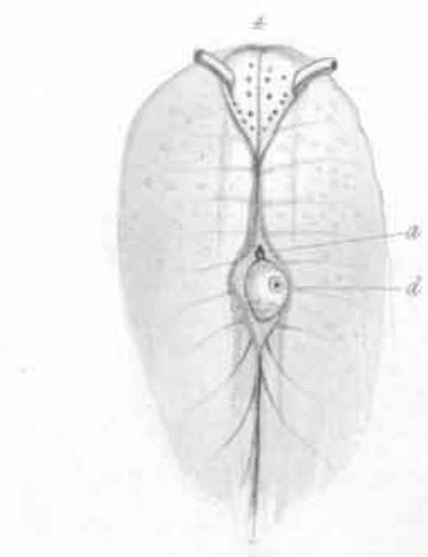

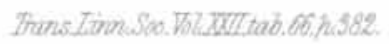
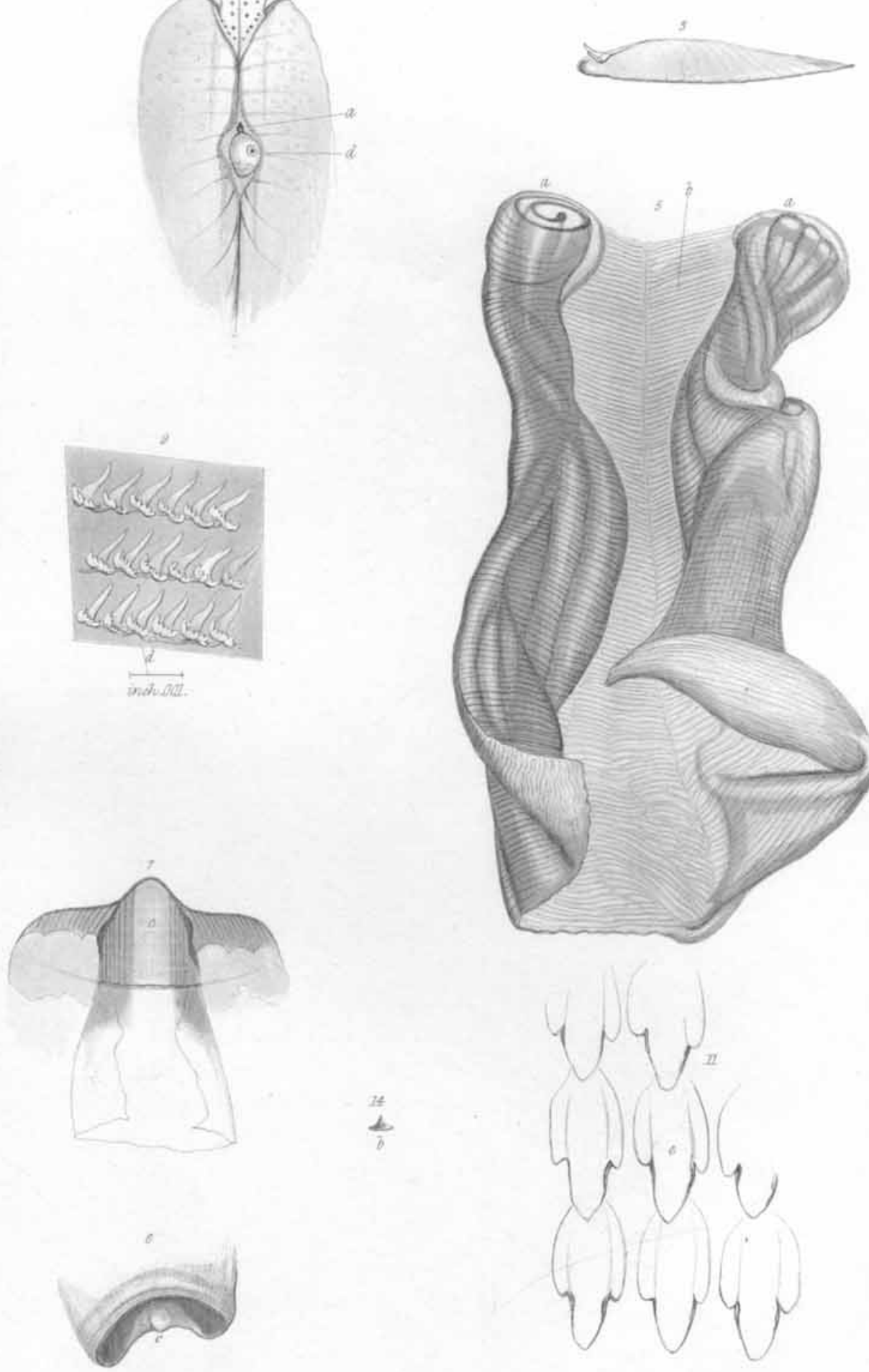

$\frac{14}{b}$
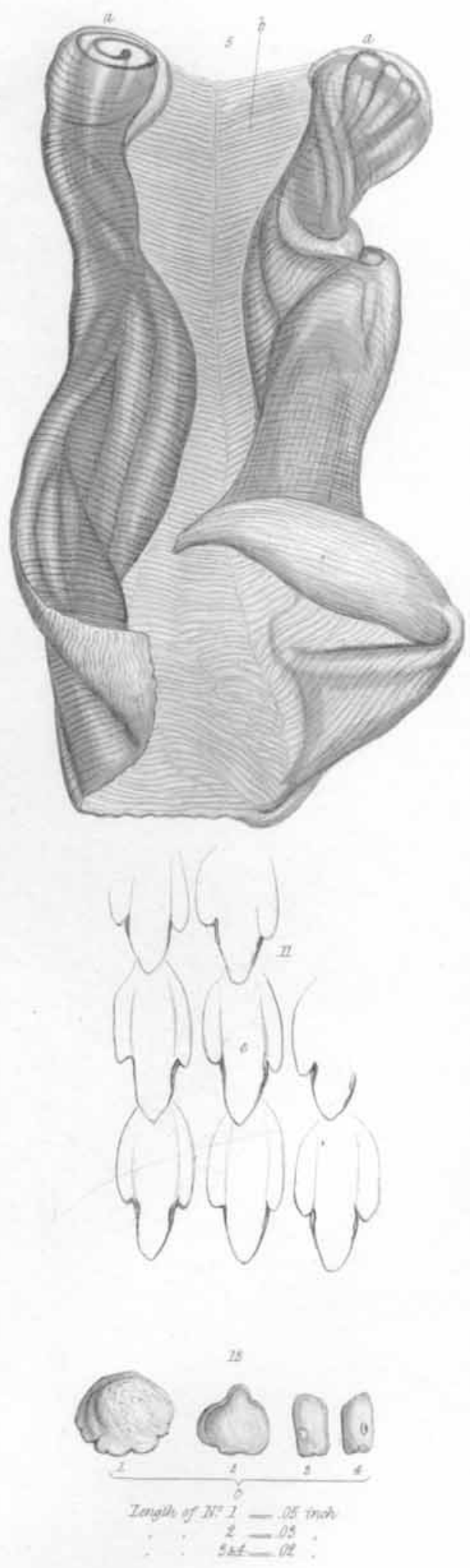

G.Jarnato.to 